\title{
Racial/Ethnic Variation in Parent Expectations for Antibiotics: Implications for Public Health Campaigns
}

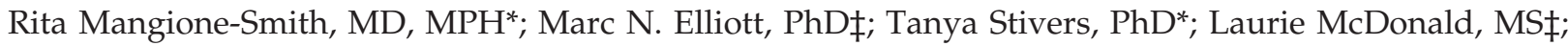

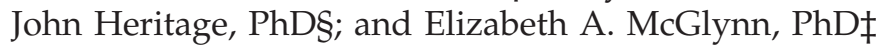

\begin{abstract}
Context. Widespread overuse and inappropriate use of antibiotics are a major public health concern. Little is known about racial/ethnic differences in parents seeking antibiotics for their children's upper respiratory illnesses.

Objective. To examine racial/ethnic differences in parent expectations about the need for antibiotics and physician perceptions of those expectations.

Design. We conducted a nested, cross-sectional survey of parents who were coming to see their child's pediatrician because of cold symptoms between October 2000 and June 2001. Parents completed a previsit survey that collected information on demographics, their child's illness, and a 15-item previsit expectations inventory that included an item asking how necessary it was for the physician to prescribe antibiotics. Physicians completed a postvisit survey that collected information on diagnosis, treatment, and whether the physician perceived the parent expected an antibiotic. The encounter was the unit of analysis. Multivariate logistic regression analyses were performed to evaluate predictors of dichotomized parental expectations for antibiotics, dichotomized physician perceptions of those expectations, diagnostic patterns, and antibiotic-prescribing patterns.
\end{abstract}

Setting. Twenty-seven community pediatric practices in the Los Angeles, Calif, metropolitan area.

Participants. A volunteer sample of 38 pediatricians (participation rate: 64\%) and a consecutive sample of 543 parents (participation rate: $83 \%$; 15 participating for each enrolled pediatrician) seeking care for their children's respiratory illnesses. Pediatricians were eligible to participate if they worked in a community-based managed care practice in the Los Angeles area. Parents were eligible to participate if they could speak and read English and presented to participating pediatricians with a child 6 months to 10 years old who had cold symptoms but had not received antibiotics within 2 weeks.

Main Outcome Measures. Parental beliefs about the necessity of antibiotics for their child's illness, physician perceptions of parental expectations for antibiotics, bacterial diagnosis rates, and antibiotic-prescribing rates.

Results. Forty-three percent of parents believed that antibiotics were definitely necessary, and $27 \%$ believed that they were probably necessary for their child's ill-

From the *Department of Pediatrics, University of California, Los Angeles, California; ŁRAND, Santa Monica, California; and §Department of Sociology, University of California, Los Angeles, California.

Received for publication Jul 11, 2003; accepted Dec 1, 2003.

Dr Stivers' present address is Max Planck Institute for Psycholinguistics, Nijmegan, The Netherlands.

Address correspondence to Rita Mangione-Smith, MD, MPH, Department of Pediatrics, University of California, 10833 LeConte Ave, Los Angeles, CA 90095-1752. E-mail: ritams@ucla.edu

PEDIATRICS (ISSN 0031 4005). Copyright (C) 2004 by the American Academy of Pediatrics. ness. Latino and Asian parents were both $17 \%$ more likely to report that antibiotics were either definitely or probably necessary than non-Hispanic white parents. Physicians correctly perceived that Asian parents expected antibiotics more often than non-Hispanic white parents but underestimated the greater expectations of Latino parents for antibiotics. Physicians also correctly perceived that parents of children with ear pain or who were very worried about their child's condition were significantly more likely to expect antibiotics. Physicians were $7 \%$ more likely to make a bacterial diagnosis and $21 \%$ more likely to prescribe antibiotics when they perceived that antibiotics were expected.

Conclusions. Parent expectations for antibiotics remain high in Los Angeles County. With time, traditional public health messages related to antibiotic use may decrease expectations among non-Hispanic white parents. However, both public health campaigns and physician educational efforts may need to be designed differently to reach other racial/ethnic groups effectively. Despite public health campaigns to reduce antibiotic overprescribing in the pediatric outpatient setting, physicians continue to respond to parental pressure to prescribe them. To effectively intervene to decrease rates of inappropriate antibiotic prescribing further, physicians need culturally appropriate tools to better communicate and negotiate with parents when feeling pressured to prescribe antibiotics. Pediatrics 2004;113:e385-e394. URL: http://www.pediatrics.org/cgi/content/full/113/5/e385; $A n$ tibiotic prescribing, parent expectations, racial/ethnic variation.

ABBREVIATIONS. CDC, Centers for Disease Control and Prevention; AWARE, California Alliance Working for Antibiotic Resistance Education; URI, upper respiratory infection; CI, confidence interval; AOM, acute otitis media.

lthough antibiotics have little or no benefit
for the common cold, nearly one-third of pa-
tients diagnosed with this condition receive an antibiotic prescription. ${ }^{1}$ Based on the prevalence of bacterial infections, $55 \%$ of antibiotic prescriptions for acute respiratory illnesses in 1998 were in excess of expected prescribing rates. ${ }^{1}$ The excessive use of outpatient antibiotics in the pediatric population has contributed to the rapid development of resistance in many strains of Streptococcus pneumoniae. ${ }^{2}$

During the mid-1990's, the general overuse and inappropriate use of antibiotics was recognized as a major public health threat in the United States. Prior research suggests that a more informed public will make fewer demands for unnecessary antibiotics. ${ }^{3-5}$ As a result, the Centers for Disease Control and 
Prevention (CDC), in collaboration with universities, pharmaceutical companies, health delivery systems, and other partners, developed the "Public Action Plan to Combat Antimicrobial Resistance." ${ }^{\prime 6}$ As part of this effort, the CDC provides program support for several campaigns around the United States that are focusing on promoting appropriate antibiotic use. One of these campaigns is the California Alliance Working for Antibiotic Resistance Education (AWARE) program.

Temporal trends suggest that the CDC campaign has affected antibiotic-prescribing rates. Among children $<15$ years old, significant decreases were observed in visit-based rates of antibiotic prescribing for pharyngitis (13\% decrease) and upper respiratory infection (URI) (38\% decrease) between 1989-1990 and $1999-2000 .^{7}$ Despite these improvements, antibiotics were still prescribed for $22 \%$ of children diagnosed with URI, and no decrease in prescribing rates was observed for bronchitis (77\% rate).

There were also no decreases in prescribing rates for otitis media $(80 \%$ rate) or sinusitis ( $77 \%$ rate); however, antibiotic prescribing for many of these cases may represent appropriate antibiotic use for bacterial illnesses. ${ }^{7}$ Although visit-based rates of antibiotic prescribing declined for both African American and white children, rates were higher for white children in 1989-1990, 1993-1994, and 1997-1998 (L. McCaig, MPH, written communication, 2003).

Physicians' perceptions about parent expectations for antibiotics have been shown to predict inappropriate prescribing. ${ }^{8-10}$ However, to date, no published studies have examined whether there are racial/ethinic differences in parent expectations for antibiotics, whether physicians perceive any differences in these expectations, or how these expectations might influence antibiotic-prescribing patterns for different racial/ethnic groups.

This study's 4 main objectives are to 1) determine whether parent expectations for antibiotics vary by race and ethnicity, 2) examine the main factors influencing a physician's decision to make a bacterial diagnosis, 3) identify the main factors influencing the decision to prescribe antibiotics, and 4) examine the role that race and ethnicity play in these decisions. These findings may provide insights for designing future public education campaigns.

\section{DESIGN/METHODS}

\section{Study Design}

We conducted a nested, cross-sectional study of 543 parents and 38 pediatricians in 27 community pediatric practices around Los Angeles County, California. Encounters were nested within physicians who were nested within practices. Measurements were only taken at 1 point in time. The sampling frame was constructed by using 2 methods. First, the medical directors of 2 major health plans in southern California provided lists of pediatricians in their plans. Second, we used the Internet to identify pediatricians belonging to various health maintenance organizations and independent practice associations in southern California. The combined sampling frame included 59 pediatricians in 43 practices. We began recruitment by contacting physicians in the sample by telephone to describe the study. If requested, project staff met face-to-face with interested physicians to discuss the study in more detail. Physicians were told that the purpose of the study was to examine parent expectations, doctor-parent communica- tion, and parent satisfaction with acute care visits. To decrease potential Hawthorne effects on the study outcomes, physicians were not informed that 1 of the main objectives of the study was to examine the relationship between parental expectations and physician antibiotic-prescribing decisions. The University of California, Los Angeles General Campus Institutional Review Board allowed this withholding of information under the condition that the physicians be debriefed at the end of the study about the main study objectives.

For a 1- to 3-week period, all parents who brought their child to see a participating physician were screened for eligibility in the waiting room of the physician's office until 15 apparently eligible parents agreed to participate. The study description provided to parents was the same as the description provided to physicians. To be eligible for participation, parents had to present because their child was having URI symptoms (cough, nasal congestion, ear pain, or throat pain). The child had to be between the ages of 6 months and 10 years and without antibiotics during the prior 2 weeks. The parent had to be able to speak and read English, and the visit had to occur between October 2000 and June 2001. All physician and parent participants gave written, informed consent. All study procedures were reviewed and approved by the University of California, Los Angeles General Campus Institutional Review Board.

\section{Data-Collection Procedures}

Before the visit, parents completed a self-administered previsit questionnaire that collected information on their demographics, their expectations for the visit, their child's current symptoms, the duration of their child's illness in days, their level of worry about their child's illness, whether their child attended day care or preschool, whether the physician being seen was their child's primary medical doctor, and if so, for how long. After the visit, physicians completed a self-administered postvisit questionnaire that included information on their physical examination findings, their diagnosis, the treatments they suggested or prescribed, their perceptions of parent expectations for the visit, and their level of diagnostic uncertainty. Diagnosis was indicated by selecting 1 of the following choices from a checklist: acute otitis media (AOM), asthma, bacterial bronchitis, bacterial pneumonia, bronchiolitis, conjunctivitis, croup, mycoplasma infection, otitis externa, otitis media with effusion, streptococcal pharyngitis, sinusitis, viral bronchitis, viral pharyngitis, viral pneumonia, viral stomatitis, and viral URI. The physician could also write in an alternate diagnosis rather than selecting 1 from the list provided.

Parent expectations for antibiotics were assessed by asking the parent to respond to the following question: "How necessary do you think it is for the doctor to prescribe an antibiotic for your child?" This item was scored on a 5-point scale (definitely necessary: 1; probably necessary: 2; uncertain: 3 ; probably unnecessary: 4; definitely unnecessary: 5). Responses then were dichotomized such that a rating of 1 or 2 was labeled "antibiotics necessary," whereas a rating of 3,4 , or 5 was labeled "antibiotics unnecessary."

The parent's level of anxiety about their child's current illness was assessed by using a previously validated survey item that assesses a patient's anxiety about his/her current illness. ${ }^{11}$ This item was adapted for the pediatric setting and asked the parent to respond to the following statement: "How worried are you about your child's health today?" Response options were not very worried (1), somewhat worried (2), very worried (3), and extremely worried (4). Responses to the item then were dichotomized with ratings of 3 or 4 labeled "worried" and ratings of 1 or 2 being labeled "not very worried."

Physician perceptions of parent expectations for antibiotics were measured by asking the physician to respond to the following statement: "At the beginning of this visit, this parent expected me to prescribe an antibiotic." The question was phrased in this way to encourage the physician to think about his/her perceptions of the parent's expectations before the physician had made an effort to educate the parent about the appropriateness of antibiotics for the child's illness. This survey item was scored on a 5-point Likert scale (strongly agree: 1; somewhat agree: 2; uncertain: 3; somewhat disagree: 4; strongly disagree: 5 ). Responses then were dichotomized such that a rating of 1 or 2 was labeled "physician perceives a parental expectation for antibiotics," whereas a rating 
of 3,4 , or 5 was labeled "physician perceives no parental expectation for antibiotics."

\section{Analytic Methods}

For all analyses, the physician-parent encounter was the unit of analysis. We tested the bivariate relationships between our hypothesized predictor and outcome variables by using the $\chi^{2}$ test of independence. Bivariate relationships were examined between each of a single set of candidate predictor variables and 1) parental expectations for antibiotics and 2) physician perceptions of parental expectations. This set of predictor variables included symptoms (fever, cough, congestion/runny nose, ear pain, ear tugging, sore throat, or vomiting); duration of illness; parent anxiety level; history of chronic illness (eg, asthma or recurrent ear infections); past experience with the physician regarding receiving antibiotics for ear infections, colds, and sore throat; day of the week; whether the child could attend day care when sick; whether the family planned to take a vacation during the next week; how long the parent had known the child's physician; the child's age; the parent's age; parent/child race/ethnicity; the parent's level of education; the parent's annual income; the physician's gender, age $(<40,40-65$, or $>65$ years old), and race/ethnicity; and whether the parent's and physician's race/ethnicity were concordant. Predictor variables that had a significant bivariate relationship $(P<$ .05) with either parent expectations for antibiotics or physician perceptions of these expectations were retained for multivariate models of both outcomes to produce comparable multivariate models.

$\phi$ coefficients and confidence intervals (CIs) were calculated to assess the correlation between parental expectations for antibiotics and physician perceptions of these expectations.

Bivariate relationships were examined also between each of a single set of candidate predictor variables and 1) assigning a bacterial diagnosis (AOM, bacterial pneumonia, mycoplasma infection, streptococcal pharyngitis, and sinusitis) and 2) prescribing an antibiotic. This set of predictor variables included parent expectations for antibiotics; physician perceptions of parent expectations; symptoms (fever, cough, congestion/runny nose, ear pain, ear tugging, sore throat, or vomiting); duration of illness; parent anxiety level; history of chronic illness (eg, asthma or recurrent ear infections); past experience with the physician regarding receiving antibiotics for colds and sore throat; physical examination findings (general appearance, appearance of the tympanic membranes, presence/type of rhinorrhea, fever, appearance of the throat, and lung findings); the physician's level of certainty about his/her diagnosis; whether there was a local influenza epidemic; patient load for the day (slow, average, very busy, or extremely busy); day of the week; whether the child could attend day care when sick; whether the family planned to take a vacation during the next week; how long the parent had known the child's physician; the child's age; the parent's age; parent/child race/ethnicity; the parent's level of education; the parent's annual income; the physician's gender, age, and race/ethnicity; and whether the parent's and physician's race/ethnicity were concordant. Predictor variables that had a significant bivariate relationship $(P<.05)$ with either assigning a bacterial diagnosis or prescribing antibiotics were retained for multivariate models of both outcomes to produce comparable multivariate models.

For the purposes of this study, the diagnoses coded as viral were all cases of bronchitis (regardless of whether the physician checked off bacterial bronchitis or viral bronchitis on the postvisit survey), bronchiolitis, croup, viral pharyngitis, viral pneumonia, viral stomatitis, and viral URI. All cases of bronchitis were coded as viral illnesses because bacterial bronchitis is considered a rare event in the otherwise healthy pediatric population..$^{12}$ If the physician only selected asthma, conjunctivitis, otitis externa, or otitis media with effusion from the list, with no other diagnoses indicated (16\% of cases), the case was excluded from all analyses related to assigning bacterial diagnoses. Oral and injectable antibacterial drugs were considered antibiotics for analysis purposes. Topical antibiotics and all other antimicrobials prescribed or administered (eg, antivirals) were not included in analyses related to antibiotic prescribing.

As noted above, the results of bivariate analyses guided development of 4 multivariate logistic regression models such that 2 pairs of parallel models were derived. All models allowed independent physician intercepts. These intercept effects were not reported for individual physicians, but their magnitudes were summarized to assess the importance of unmeasured physician characteristics. All models accounted for the full hierarchical structure of patients within physicians within practices. For each model, odds ratios and 95\% CIs were estimated for all predictor variables. Multivariate-adjusted proportions with $95 \%$ CIs then were calculated to estimate the marginal effects of each significant predictor variable, using actual values for all independent variables other than the 1 under consideration. These proportions estimate the change in the probability of the outcome if only the 1 predictor variable in question changes, with all other predictors held constant.

The first logistic regression model examined the relationship between a series of patient, parent, and physician characteristics and the outcome of parent expectations for antibiotics. The second model predicted physician perceptions of parent expectations from the same set of variables used in the first model.

The third logistic model predicted whether a physician would make a bacterial diagnosis from the child's illness characteristics, physical examination findings, parent demographics, parent anxiety level and expectations for antibiotics, and physician perceptions of parent expectations for antibiotics.

The fourth logistic regression model predicted whether a physician would prescribe antibiotics from the same set of variables used in the third model.

Stata 8.0 (Stata Corporation, College Station, TX) was used for all analyses. ${ }^{13}$

\section{RESULTS}

Of 678 parents invited to participate, 570 agreed $(84 \%)$. Twenty-seven participating parents were determined later to be ineligible, because their children did not have an eligible diagnosis (eg, earwax impaction, skin rash, or gastroenteritis), yielding a final sample of 543 participating parents of 651 invited eligibles (eligible participation rate: $83 \%$ ). Of the 59 eligible pediatricians, 38 agreed to participate $(64 \%$ participation rate). Between 1 and 4 pediatricians were recruited from each of 27 practices.

Parents were 34 years old on average and had a median annual income of approximately \$40 000 . Eighty-three percent were female, 53\% were Latino, and most parents $(68 \%)$ had attended at least some college (Table 1). Parents in the study sample underrepresented Asians, non-Hispanic whites, and those with no secondary education compared with the adult population of Los Angeles County in 2000 (Table $1 ; P<.05$ for all differences noted).

Seventy-one percent of participating physicians were male, $71 \%$ were non-Hispanic white or Asian, and $42 \%$ were between 40 and 65 years old (Table 2 ). Compared with California physicians (1998-1999 data), physicians in the study were more likely to be male, less likely to be non-Hispanic white, and more likely to be Latino or "other" race/ethnicity (Table 2; $P<.05$ for all differences noted). ${ }^{14,15}$ Study physicians had a similar age distribution to California physicians

\section{Parent Expectations for Antibiotics and Physician Perceptions of Expectations}

The overall correlation between parent expectations for antibiotics and physician perceptions of those expectations was statistically significant but qualitatively small ( $\phi$ coefficient: .084; $P=.05$ ).

Of the parents in our study, $70 \%$ indicated that antibiotics were either probably or definitely necessary for their child's illness, whereas physicians per- 
TABLE 1. Parent Demographics

\begin{tabular}{|c|c|c|c|}
\hline Characteristics & $n$ & Result & $\begin{array}{l}\text { Los Angeles County } \\
\text { Census: } 2000^{21}\end{array}$ \\
\hline Mean age & 543 & 34 y (SD: 8 y) & N/A \\
\hline Gender (female) & 450 & $83 \%$ & $\mathrm{~N} / \mathrm{A}$ \\
\hline \multicolumn{4}{|l|}{ Race/Ethnicity } \\
\hline White (non-Hispanic) & 146 & $27 \% *$ & $31 \%$ \\
\hline Latino & 290 & $53 \% *$ & $45 \%$ \\
\hline African American & 64 & $11 \%$ & $10 \%$ \\
\hline Asian & 43 & $8 \% *$ & $12 \%$ \\
\hline Education & & & For adults aged $\geq 25 \mathrm{y}$ \\
\hline$\leq 8$ th grade & 16 & $3 \% *$ & $16 \%$ \\
\hline Some high school & 70 & $13 \%$ & $14 \%$ \\
\hline High school graduate or some college & 326 & $60 \% *$ & $45 \%$ \\
\hline Bachelors degree & 131 & $24 \%$ & $25 \%$ \\
\hline \multicolumn{4}{|l|}{ Annual income } \\
\hline$<20000$ & 100 & $18 \%$ & $30 \%(<25000)$ \\
\hline $20000-40000$ & 177 & $33 \%$ & $27 \%(25000$ to $<50000)$ \\
\hline $41000-80000$ & 162 & $30 \%$ & $28 \%(50000$ to $<100000)$ \\
\hline$>80000$ & 104 & $19 \%$ & $15 \%(\geq 100000)$ \\
\hline
\end{tabular}

${ }^{*} P<.05$ for comparison of the study population to the Los Angeles County adult population.

TABLE 2. Physician Demographics

\begin{tabular}{lrccc}
\hline \multicolumn{1}{c}{ Characteristics } & $n$ & Proportion & $\begin{array}{c}\text { California } \\
\text { Pediatricians, 199915 }\end{array}$ & $\begin{array}{c}\text { California } \\
\text { Physicians, 1998 } 14,15\end{array}$ \\
\hline Gender (male) & 27 & $71 \%^{*}$ & $51 \%$ & \\
Race/ethnicity & 16 & $42 \% *$ & & $73 \%$ \\
White & 11 & $29 \%$ & $19 \%$ \\
Asian & 5 & $13 \% *$ & $4 \%$ \\
Latino & 3 & $8 \%$ & $3 \%$ \\
African American & 3 & $8 \% *$ & $1 \%$ \\
Other & 13 & $36 \%$ & $37 \%(<44$ y) \\
Age, y & 17 & $42 \%$ & & $42 \%(45-65 \mathrm{y})$ \\
$<40$ & 8 & $22 \%$ & & $21 \%(>65 \mathrm{y})$ \\
$40-65$ & & &
\end{tabular}

${ }^{*} P<.05$ for comparison between the study population and the reference group.

ceived that only $36 \%$ of parents expected antibiotics for their child. Parents expected antibiotics in $81 \%$ of cases that ultimately resulted in a bacterial diagnosis and in $66 \%$ of cases that ultimately resulted in a viral diagnosis. Physicians tended to underestimate the proportion of cases in which parents expected antibiotics, with physicians perceiving an expectation for antibiotics in $55 \%$ of cases that resulted in a bacterial diagnosis and $32 \%$ of cases that resulted in a viral diagnosis $(P<.0001$ in each case, comparing parent expectations to physician perceptions of expectations). Furthermore, within diagnosis type, physicians perceived parental expectations no more often when they were present than when they were absent (34\% vs $27 \%$ for viral diagnoses and $61 \%$ vs $53 \%$ for bacterial diagnoses; $P>.20$ in each case).

Parent racial/ethnic group was significantly associated with parental expectations for antibiotics, physician perceptions of parental expectations for antibiotics, and parental anxiety level (Table 3). NonHispanic white parents were less likely to expect antibiotics than Latino, Asian, and African American parents $(P<.05)$. Physicians were more likely to perceive that Asian and African American parents expected antibiotics than non-Hispanic white parents $(P<.05)$. Both Latino and African American

TABLE 3. Variation in Expectations, Perceptions, Diagnosis, and Prescribing by Parent/Child Race/Ethnicity

\begin{tabular}{|c|c|c|c|c|}
\hline \multirow[t]{2}{*}{ Characteristic } & \multicolumn{4}{|c|}{ Parent Race/Ethnicity } \\
\hline & White & Latino & Asian & African American \\
\hline & $n=146$ & $n=290$ & $n=43$ & $n=64$ \\
\hline Parents expecting antibiotics, \%† & $51^{*}$ & 80 & 74 & 67 \\
\hline Parents perceived as expecting antibiotics by physician, $\% \dagger$ & 29 & 36 & 53 & 49 \\
\hline Parents who were very worried about their child's condition, $\% \dagger$ & 17 & 43 & 23 & 41 \\
\hline Bacterial diagnosis rate (for children), $\%$ & 34 & 37 & 35 & 28 \\
\hline Antibiotic-prescribing rate (for children), \% & 37 & 43 & 40 & 38 \\
\hline Antibiotic-prescribing rate for viral infections, \%‡ & 13 & 16 & 13 & 23 \\
\hline Antibiotic-prescribing rate for bacterial infections, \% & 88 & 93 & 93 & 78 \\
\hline
\end{tabular}

* Percent (number in racial ethnic group with characteristic out of total number in racial/ethnic group).

+ Racial/ethnic groups are significantly different from one another for these characteristics; $P<.05$.

$\ddagger$ Among those who received this type of diagnosis; some diagnoses were neither viral nor bacterial (eg, asthma or allergies). 
parents expressed more worry about their child's condition than non-Hispanic white parents did $(P<$ $.05)$.

Neither parent expectations nor physician perceptions of those expectations were influenced by parent-physician racial/ethnic concordance (Table 4). The correlation between parent expectations and physician perceptions of those expectations also was not influenced by parent-physician racial/ethnic concordance in most cases (Table 4, row 3 ). In all but 1 case the correlations ( $\phi$ coefficients) were $<.25$. The only significant correlation between parent expectations and physician perceptions occurred for African American parents seeing physicians of discordant race/ethnicity (Table 4 ) ( $\phi$ coefficient: .37; $P<.05$ ).

Multivariate-adjusted proportions indicated that the probability a parent would believe antibiotics were necessary for his/her child increased significantly if the child had ear pain (16\% increase), if the parent was Asian or Latino (17\% increase for both groups, relative to non-Hispanic white parents), or if the parent was very worried about his/her child's illness $(15 \%$ increase) (Table 5 , column $2, P<.05)$.

Eighty percent of the parents reported that they were seeing their child's primary physician. Bivariate analyses indicated that parents who had known their child's physician for $<1$ year were significantly more likely to expect antibiotics than parents who had known their child's physician for $\geq 1$ year $(78 \%$ vs $67 \% ; P<.05)$. However, in multivariate results, this variable was not a significant predictor of parent expectations or physician perceptions of parent expectations for antibiotics.

Having a child who attended group day care and who could not attend when sick did not significantly increase parent expectations for antibiotics, physician perceptions that antibiotics were expected by the parent, or actual antibiotic-prescribing rates $(P>$ .2).

For physician perceptions of parent expectations for antibiotics, multivariate-adjusted proportions indicated that physicians accurately perceived that parents who presented with children having ear pain or who were very worried about their child's illness were significantly more likely to expect antibiotics (Table 5, column 3; $P<.05$ ). Physicians were $22 \%$ more likely to perceive an expectation for antibiotics from an Asian parent compared with a non-Hispanic white parent (Table 5, column 3; $P<.05$ ). However, physicians underestimated the probability that Latino parents expected antibiotics. If a child had a history of chronic illness (eg, asthma), the probability that the physician would perceive the parent as expecting antibiotics decreased by $7 \%$ (Table 5 , column 4; $P<.05)$. Male physicians were significantly more likely to perceive parents as expecting antibiotics than were female physicians $(P<.05)$.

Individual physician characteristics other than gender, age, and race/ethnicity were assessed by examining the set of individual physician intercepts in the multivariate model (data not shown). These intercepts were strongly associated with perceived parental expectations for antibiotics. Controlling for other factors in the model, the mean absolute mult-

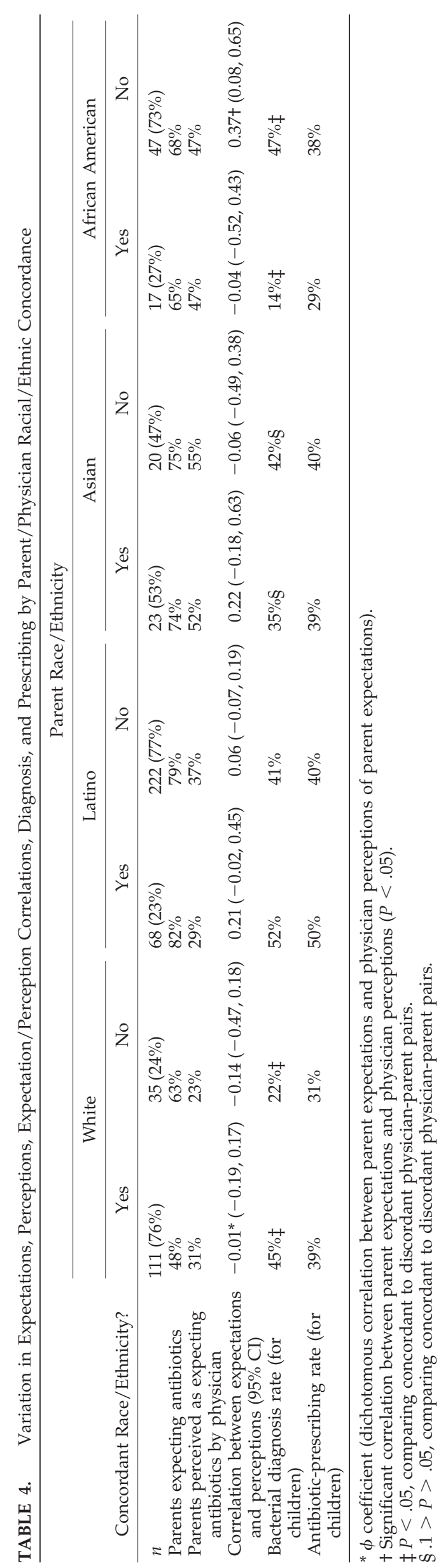


TABLE 5. Multivariate-Adjusted Predictors of Parent Expectations for Antibiotics and Physician Perceptions of Parent Expectations for Antibiotics

\begin{tabular}{|c|c|c|c|c|}
\hline Predictor Variable & $\begin{array}{c}\text { Change in Probability } \\
\text { of Parent Expecting } \\
\text { Antibiotics }\end{array}$ & $95 \% \mathrm{CI}$ & $\begin{array}{l}\text { Change in Probability that } \\
\text { Physician Perceives an } \\
\text { Expectation for Antibiotics }\end{array}$ & $95 \%$ CI \\
\hline $\begin{array}{l}\text { Child or parent complains that child } \\
\text { has ear pain }\end{array}$ & $16.0 \% *$ & $5.3 \%, 26.7 \%$ & $18.4 \% *$ & $9.7 \%, 27.1 \%$ \\
\hline Child sick for $<2$ days & $6.5 \%$ & $-2.7 \%, 15.7 \%$ & $9.3 \%$ & $-0.6 \%, 19.2 \%$ \\
\hline $\begin{array}{l}\text { Child has a history of chronic illness } \\
\text { (eg, asthma) }\end{array}$ & $-7.7 \%$ & $-16.8 \%, 1.4 \%$ & $-7.3 \% *$ & $-15 \%,-0.2 \%$ \\
\hline $\begin{array}{l}\text { Parent very worried about child's } \\
\text { current illness }\end{array}$ & $14.7 \% *$ & $5.6 \%, 23.8 \%$ & $8.6 \% *$ & $2.1 \%, 15.1 \%$ \\
\hline Parent is Latinot & $16.5 \% *$ & $5.8 \%, 27.2 \%$ & $1.6 \%$ & $-12 \%, 15.2 \%$ \\
\hline Parent is African Americant & $7.4 \%$ & $-7.5 \%, 22.3 \%$ & $4.2 \%$ & $-11.7 \%, 20.1 \%$ \\
\hline Parent is Asiant & $16.6 \% *$ & $2.3 \%, 30.9 \%$ & $21.9 \% *$ & $2.5 \%, 41.3 \%$ \\
\hline Parent has known physician for $<1 \mathrm{y}$ & $4.0 \%$ & $-4.3 \%, 12.3 \%$ & $2.0 \%$ & $-8.4 \%, 12.4 \%$ \\
\hline Physician is male & $-7.8 \%$ & $-18.6 \%, 3.0 \%$ & $38.8 \% *$ & $0.01 \%, 77.5 \%$ \\
\hline Physician age $(<40,40-65,>65$ y) & $-4.3 \%$ & $-12.7 \%, 4.1 \%$ & $-13.6 \%$ & $-35.6 \%, 8.4 \%$ \\
\hline
\end{tabular}

${ }^{*} P<.05$ for increase or decrease in probability of the outcome.

t Relative to non-Hispanic white parents.

ivariate-standardized odds ratio for the set of physician intercepts was $3.36(P<.05)$, making this the second-most important predictor of perceived expectations after physician gender. Physician age and race/ethnicity were not predictive of perceived parental expectations for antibiotics. Individual physician characteristics represented by the set of physician intercepts in the model, as well as physician gender, age, and race/ethnicity, were not significantly associated with actual parent expectations for antibiotics. Thus, there was substantial variation in perceptions from physician to physician but no corresponding differences in the actual expectations of their parent populations that were not explained by other factors in the model predicting actual parent expectations.

\section{Assigning Diagnoses and Prescribing Antibiotics}

Forty-one percent of the patients received a bacterial diagnosis (AOM, bacterial pneumonia, mycoplasma infection, streptococcal pharyngitis, and sinusitis). Antibiotics were prescribed in $46 \%$ of cases overall. Antibiotics were prescribed for $91 \%$ of bacterial diagnoses and 16\% of viral diagnoses.

In bivariate analyses, bacterial diagnosis rates and antibiotic-prescribing rates did not vary by parent/ child race or ethnicity (Table 3). However, when non-Hispanic white parents saw a racially concordant physician, they were significantly more likely to receive a bacterial diagnosis than when they saw a discordant physician (Table $4 ; 45 \%$ bacterial diagnosis rate versus $22 \% ; P<.05)$. When African American parents saw racially concordant physicians, they were significantly less likely to receive a bacterial diagnosis than when they saw a discordant physician (Table $4 ; 14 \%$ vs $47 \%$; $P<.05$ ). For Latinos and Asians, racial/ethnic concordance did not influence bacterial diagnosis rates. Antibiotic-prescribing rates were also not influenced by racial/ethnic concordance for any of the groups studied (Table 4).

Multivariate-adjusted proportions revealed that African American and Latino children were $8 \%$ and $13 \%$ less likely, respectively, to receive a bacterial diagnosis than were non-Hispanic white children who presented with the same constellation of symptoms and physical examination findings (Table 6, column 2; $P<.05$ ). In contrast, Asian children were $13 \%$ more likely to receive a bacterial diagnosis than non-Hispanic white children with the same constellation of symptoms and physical examination findings. Adjusted results did not show any increase or decrease in the probability of receiving an antibiotic based on racial or ethnic group (Table 6, column 4).

The probability that a bacterial diagnosis would be given and/or antibiotics would be prescribed also significantly increased if the visit occurred during the first 48 hours of an illness or the child had 1 of several physical examination findings (Table 6). Adjusted results also revealed that, if a physician perceived the parent as wanting antibiotics, the probability that he/she would assign a bacterial diagnosis increased by $7 \%$ (Table 6, column 2; $P<.05$ ), whereas the probability that an antibiotic would be prescribed increased by $21 \%$ (Table 6 , column $4 ; P<$ $.05)$.

\section{DISCUSSION}

We found significant differences in the expectations of parents about the necessity of prescribing antibiotics by race/ethnicity, ranging from $51 \%$ for non-Hispanic white parents to $80 \%$ for Latino parents. Prior studies have found that $48 \%$ to $65 \%$ of adult patients or parents expect antibiotics for the common cold, $, 8,16,17$ but these studies were conducted primarily in non-Hispanic white populations.

Although physicians correctly perceived that Asian parents were more likely to expect antibiotics for their children than non-Hispanic white parents, they substantially underestimated the greater expectations of Latino parents. Physicians' perceptions may be affected by differences in how parents in various ethnic groups communicate with them. Minority patients, especially those not proficient in English, are less likely to establish rapport with physicians, receive sufficient information, and be encouraged to participate in medical decision-making. ${ }^{18-20}$ English may have been a second language for a majority of the Latino parents in the current study. 


\begin{tabular}{|c|c|c|c|c|}
\hline Predictor Variable & $\begin{array}{c}\text { Change in Probability } \\
\text { of Assigning a } \\
\text { Bacterial Diagnosis }\end{array}$ & $95 \%$ CI & $\begin{array}{c}\text { Change in Probability } \\
\text { of Prescribing } \\
\text { Antibiotics }\end{array}$ & $95 \% \mathrm{CI}$ \\
\hline Child sick for $<2$ days & $10.3 \% *$ & $5.1 \%, 15.5 \%$ & $8.4 \% *$ & $2.2 \%, 14.6 \%$ \\
\hline $\begin{array}{l}\text { Presence of fever both at home and in the } \\
\text { physician's office }\end{array}$ & $6.1 \% *$ & $1.4 \%, 10.8 \%$ & $11.3 \% *$ & $4.1 \%, 14.4 \%$ \\
\hline $\begin{array}{l}\text { Abnormal appearance of the tympanic } \\
\text { membranet }\end{array}$ & $74.1 \% *$ & $64.7 \%, 83.5 \%$ & $55.0 \% *$ & $47.2 \%, 62.8 \%$ \\
\hline $\begin{array}{l}\text { Presence of purulent rhinorrhea on } \\
\text { examination }\end{array}$ & $27.3 \% *$ & $14.1 \%, 40.5 \%$ & $30.5 \% *$ & $15.6 \%, 45.4 \%$ \\
\hline $\begin{array}{l}\text { Pharyngeal erythema found in a child who } \\
\text { presented with sore throat }\end{array}$ & $16.8 \% *$ & $9.6 \%, 24.0 \%$ & $13.4 \% *$ & $2.7 \%, 24.1 \%$ \\
\hline $\begin{array}{l}\text { Presence of rhonchi or wheezing on } \\
\text { examination }\end{array}$ & $-5.1 \%$ & $-11.4 \%, 1.2 \%$ & $12.6 \% *$ & $3.3 \%, 21.9 \%$ \\
\hline Parent expects to receive antibiotics for child & $4.6 \%$ & $-1.9 \%, 11.1 \%$ & $5.0 \%$ & $-1.7 \%, 11.7 \%$ \\
\hline $\begin{array}{l}\text { Physician perceives that parent expects to } \\
\text { receive antibiotics for child }\end{array}$ & $7.4 \% *$ & $0.6 \%, 14.2 \%$ & $21.5 \% *$ & $13.0 \%, 30.0 \%$ \\
\hline Parent is Latino $\ddagger$ & $-7.6 \% *$ & $-14.9 \%,-0.3 \%$ & $-4.4 \%$ & $-11.0 \%, 2.2 \%$ \\
\hline Parent is African American $\ddagger$ & $-13.1 \% *$ & $-22.1 \%,-4.1 \%$ & $-3.0 \%$ & $-10.2 \%, 4.2 \%$ \\
\hline Parent is Asian $\ddagger$ & $13.1 \% *$ & $3.1 \%, 23.1 \%$ & $8.3 \%$ & $0.0 \%, 16.6 \%$ \\
\hline
\end{tabular}

${ }^{*} P<.05$ for increase or decrease in probability of the outcome.

+ Abnormal appearance of the tympanic membrane was defined as the physician indicating on the postvisit survey that at least 1 tympanic membrane had at least 1 of the following characteristics: bulging, perforated, retracted, purulent effusion, serous effusion, opaque/dull, or red or yellow in color. Findings consistent with otitis media with effusion, eg, serous effusion, retracted, were included because $71 \%$ of otitis media with effusion cases received antibiotics.

$\ddagger$ Relative to non-Hispanic white parents.

According to the 2000 US Census report, $28.9 \%$ of the Los Angeles County adult population reported that they spoke English less than very well and 54\% speak a language other than English at home. ${ }^{21} \mathrm{Al}-$ though parent-physician racial/ethnic concordance was not related to improved physician perceptions of parent expectations, our power to detect a relationship between these variables may have been limited by small sample sizes for concordant Latino and African American pairs.

Some of the disparity between actual and perceived expectations also might be explained by parents not making an explicit request for antibiotics. Our previous work suggests that such overt requests occur infrequently. ${ }^{22,23}$ However, we have reported previously that physicians interpret certain phrases as signaling an expectation for antibiotics (eg, when the parent uses "strep throat" rather than "sore throat" to describe the child's illness). ${ }^{24}$ The phrases used by Latinos to describe illnesses may well differ from their non-Hispanic white counterparts, which may contribute further to the mismatch in physician perceptions about parental expectations. Determining which parent-communication behaviors consistently trigger the perception that antibiotics are expected when, in fact, they are not would facilitate the development of educational interventions for physicians.

Interestingly, male providers were significantly more likely to perceive parents as expecting antibiotics than were female providers. However, parents were no more likely to expect antibiotics when seeing a male versus a female physician. In a multivariate analysis, we found that physician perceptions were associated with actual parent expectations significantly less often when the physician was male than when the physician was female $(P<.05$; results not shown). A majority of the parents in our study were female (Table 1), whereas most of the physi- cians were male (Table 2). The relative participation of a physician and a patient in an encounter has been shown to be the most equal when both the physician and the patient are female. ${ }^{25}$ Additionally, when patients interact with female physicians, they disclose more information. ${ }^{25-27}$ In the nonverbal domain of communication, women also tend to be more accurate at perceiving the emotions of others than are men. ${ }^{28}$ In the current study, male physicians may have been less proficient at determining actual parent expectations either through direct verbal communication and/or from parents' nonverbal cues and thus were more prone to incorrectly perceiving expectations for antibiotics than were female physicians.

Prior focus group work suggests that a parent's need to return to work and get their child back into day care is a primary reason for wanting antibiotics for their children's respiratory illnesses. ${ }^{3}$ However, in the current study, having a child who attended day care and who could not attend while sick did not influence parent reports that antibiotics were either probably or definitely necessary for their child. Adjusted results also indicated that seeing a physician with whom the parent had an established relationship did not increase or decrease either parent expectations for antibiotics or physician perceptions of these expectations.

Not surprisingly, parents who presented with children having ear pain were significantly more likely to expect antibiotics and to be perceived as expecting antibiotics. In a recent study, most parents indicated that their child's physician was their main source of information about the way to treat ear infections, and this is why they believed that all ear infections require antibiotics. ${ }^{29}$ Although a fair amount of controversy exists regarding the appropriate treatment of $\mathrm{AOM}^{30} 76 \%$ of ear infections are treated with antibiotics in the United States. ${ }^{1}$ The current evidence 
base, albeit flawed, ${ }^{30}$ suggests that some cases of AOM in children $>2$ years old can be treated successfully without antibiotics. ${ }^{31,32}$ If the option of watchful waiting (withholding antibiotics for 72 hours) is adopted on a wider basis by health care professionals, and this management option is presented as being reasonable to parents, parent expectations for antibiotics when their child has ear pain then might decrease.

The probability of receiving a bacterial diagnosis or an antibiotic prescription did not vary significantly overall by race or ethnic group (Table 3); however, African American patients with African American doctors and white patients with nonwhite doctors did have exceptionally low rates of bacterial diagnoses (Table 4). Because almost all African American physicians saw only African American patients, it is not clear that the low bacterial diagnosis rates observed in these dyads is a function of racial concordance or merely describes the diagnostic patterns of these physicians.

Although the absolute rates of making bacterial diagnoses and prescribing antibiotics did not vary by racial/ethnic group (Table 3), adjusted results revealed that, given the same constellation of symptoms and physical examination findings, African American and Latino children were significantly less likely to receive a bacterial diagnosis, compared with non-Hispanic white children (Table 6). In contrast, Asian children were significantly more likely to receive a bacterial diagnosis, when compared with non-Hispanic white children. A subsequent multivariate model that removed the individual physician intercepts was run in an attempt to better understand these findings (data not shown). This follow-up model revealed that most of the African American and Asians effects $(63 \%$ and $84 \%$ of the observed multivariate effects) and some (32\%) of the Latino effect are attributable to differential diagnostic patterns of physicians for these different racial/ethnic groups. Controlling for all factors in Table 6 except for the individual physician intercepts, we find the coefficients for Latinos and African Americans become marginal $(P=.07$ and $P=.15$, respectively), and the coefficient for Asians loses all significance $(P$ $=.65)$. This indicates that African Americans and Latinos tend to go to physicians who make many bacterial diagnoses for non-African Americans and non-Latinos but tend to make substantially fewer bacterial diagnoses (eg, average numbers) for African Americans and Latinos. Similarly, Asians tend to go to physicians who make few bacterial diagnoses for non-Asians, but tend to make substantially more (eg, average numbers) bacterial diagnoses for Asians. In each case, the selective diagnostic behavior based on patient race/ethnicity for physicians happens to be balanced by the overall tendencies of these physicians to make bacterial diagnoses, resulting in no net difference overall (see Table 3, row 4). This differential behavior toward parents and children of different racial/ethnic groups may reflect variance in the way these groups of parents communicated with their child's physician. It is possible that Asian parents more forcefully communicated their belief that their child had an illness treatable with antibiotics than non-Hispanic white parents and that African American and Latino parents did this less often than white parents. However, this finding also may represent physician bias in the management of patients belonging to different racial/ethnic groups, which has been observed in several prior studies in the adult population. ${ }^{33-36}$

Although adjusted results indicated fewer bacterial diagnoses for African American and Latino patients, compared with non-Hispanic white patients, this did not translate to lower adjusted rates of receiving antibiotics. This may indicate that these groups were more likely to receive antibiotics for inappropriate indications (ie, nonbacterial illnesses). However, because only $16 \%$ of the viral cases received antibiotics, we did not have the statistical power to test this hypothesis.

Similar to prior studies, we found that several different physical examination findings were predictive of both assigning a bacterial diagnosis and prescribing an antibiotic (Table 6). ${ }^{37-39}$ Although actual parent expectations were not a significant predictor of either of these outcomes, physician perceptions that a parent expected antibiotics were, increasing the probability of assigning a bacterial diagnosis by $7 \%$ and of prescribing an antibiotic by $21 \%$. These findings are consistent with several studies conducted in the mid- to late 1990s. $8,10,16,17$

Physicians in 1 prior study reported that they were more likely to prescribe antibiotics for a child with URI symptoms if he or she had been ill for $\geq 3$ days. ${ }^{37}$ In contrast, we found that as the duration of illness increased, physicians were significantly less likely to both assign a bacterial diagnosis and prescribe an antibiotic (Table 6). This remained true even in cases in which the child had been ill for $>7$ days. This difference may be explained by how the 2 studies were designed. Davy et $\mathrm{al}^{37}$ presented physicians with written clinical scenarios and assessed the likelihood of issuing a prescription for antibiotics, given certain clinical criteria. In the current study, we assessed parent reports of duration of symptoms in the previsit survey and then assessed physician prescribing for the visit. It is possible that parents in our study were not asked by the physician or did not volunteer information about the duration of their child's illness, thus negating the influence of this factor on the physician's decision-making process. Alternatively, it is possible that what physicians report they would do, given a certain set of clinical circumstances on a survey, may be measurably different from their actual practice, in which early presentation may be perceived by physicians as a proxy for parental concern.

In 1995, the CDC launched a national campaign to reduce antimicrobial resistance through promotion of more appropriate antibiotic use. Thus, despite the CDC's national campaign, physicians continue to respond to perceived pressure to prescribe. McCaig et $\mathrm{al}^{7}$ recently reported a $40 \%$ drop in the number of antibiotic prescriptions issued nationally per 1000 people aged $\leq 15$ years over the past 10 years. However, visit-based antibiotic-prescribing rates only sig- 
nificantly declined for pharyngitis and URI, whereas prescribing rates for otitis media, sinusitis, and bronchitis remained stable. This suggests that, although visits for these conditions are decreasing based on population-based rates of antibiotic prescribing, once a patient comes into the physician's office, the chances he/she will receive antibiotics for certain respiratory infections have largely remained unchanged. It is possible that changes in insurance coverage or increasing copays for the US population have resulted in decreased visit rates for minor illnesses. It is possible also that the efforts to educate the public on which illnesses require antibiotics have resulted in fewer visits to the physician. However, the results indicate that interventions with physicians, particularly giving them techniques to use when feeling pressured to prescribe in the office setting, are needed.

Our results also suggest that expectations for antibiotics among Latino and Asian parents are substantially higher than any of the populations studied previously, which might be explained by varying cultural belief systems with regard to the effectiveness of antibiotics for respiratory illnesses. Many of the public health campaign materials focus on educating the public about the difference between viruses and bacteria and that only bacterial infections require antibiotics. However, focus groups conducted by the California Medical Association Foundation AWARE Project in early 2002 with 5 groups of Latino parents in Santa Barbara, Santa Maria, Lompoc, and Los Angeles, California, revealed that the words "bacteria" and "virus" are not meaningful to this population (AWARE Project, unpublished data, 2002). Both are considered "germs," and it was thought by these parents that all infections caused by germs should be treated with antibiotics. Thus, it is possible that alternative educational messages may be needed to reach these groups of parents effectively. Similarly, when a physician explains that a child has a cold or a viral infection, it might be misinterpreted by some parents as an illness that requires antibiotics. Thus, physicians also may need to alter the types of educational messages they are using when working with these diverse populations of parents.

\section{LIMITATIONS}

This study has several limitations. First, it was conducted in 1 geographic location; thus, the results may not be applicable to different populations of parents and physicians in different locations. Second, we had a small physician population $(n=38)$, which underrepresented female pediatricians $(29 \%)$. It is possible also that, under normal circumstances when these particular physicians are not being observed, pressure to prescribe antibiotics may be acted on more frequently. In a prior study with a similar study design, a significant Hawthorne effect was observed on both bacterial diagnosis rates and antibiotic prescribing patterns. ${ }^{40}$ Thus, it is possible that the results of the current study represent a lowerbound estimate of the impact of parental pressure on these outcomes. Although we found no influence of racial/ethnic concordance on the physician's ability to perceive parent expectations accurately, our small sample sizes for concordant pairs among African American and Latino physicians and parents may have limited our ability to detect these relationships.

\section{CONCLUSIONS}

Parent expectations for antibiotics remain high in Los Angeles County. With time, traditional public health messages related to antibiotic use may decrease expectations among non-Hispanic white parents. However, both public health campaigns and physician educational efforts may need to be designed differently to reach other racial/ethnic groups effectively. Despite public health campaigns to reduce antibiotic overprescribing in the pediatric outpatient setting, physicians continue to respond to parental pressure to prescribe. To intervene effectively to decrease rates of inappropriate antibiotic prescribing further, physicians need culturally appropriate tools to better communicate and negotiate with parents when feeling pressured to prescribe antibiotics. We believe that the most important questions to address in light of this study's results are: 1) Do parents communicate their expectations for antibiotics to their child's physician, and if so, how? 2) What parent-communication behaviors lead to both accurate and inaccurate physician perceptions that antibiotics are desired? 3) Does physician-parent communication related to these issues vary by parent race/ethnicity or by racial/ethnic concordance? 4) What physician-communication behaviors lead to increased satisfaction despite not receiving expected antibiotics? Answering these questions will facilitate the development of interventions to further address the problem of antibiotic overprescribing.

\section{ACKNOWLEDGMENTS}

This study was funded by Robert Wood Johnson Foundation grant 039189 .

We thank all the community physicians who agreed to participate in this study.

\section{REFERENCES}

1. Gonzales R, Malone DC, Maselli JH, Sande MA. Excessive antibiotic use for acute respiratory infections in the United States. Clin Infect Dis. 2001;33:757-762

2. Whitney CG, Farley MM, Hadler J, et al. Increasing prevalence of multidrug-resistant Streptococcus pneumoniae in the United States. N Engl J Med. 2000;343:1917-1924

3. Barden LS, Dowell SF, Schwartz B, Lackey C. Current attitudes regarding use of antimicrobial agents: results from physicians' and parents' focus group discussions. Clin Pediatr (Phila). 1998;37:665-672

4. Belongia EA, Naimi TSGCM, Besser RE. Antibiotic use and upper respiratory infections: a survey of knowledge, attitudes, and experience in Wisconsin and Minnesota. Prev Med. 2002;34:346-352

5. Bauchner H, Pelton S, Klein JO. Parents, physicians, and antibiotic use. Pediatrics. 1999;103:395-401

6. Centers for Disease Control and Prevention. Preventing emerging infectious diseases: addressing the problem of antimicrobial resistance: a strategy for the 21st century. Available at: www.cdc.gov/ncidod/ emergplan/antiresist/antimicrobial.pdf. Accessed February 28, 2003

7. McCaig LF, Besser RE, Hughes JM. Trends in antimicrobial prescribing rates for children and adolescents. JAMA. 2002;287:3096-3102

8. Mangione-Smith R, McGlynn EA, Elliott MN, Krogstad P, Brook RH. The relationship between perceived parental expectations and pediatrician antimicrobial prescribing behavior. Pediatrics. 1999;103:711-718 
9. Palmer DA, Bauchner H. Patients' and physicians' views on antibiotics. Pediatrics. 1997;99(6). Available at: www.pediatrics.org/cgi/content/ full/99/6/e6

10. Vinson DC, Lutz LJ. The effect of parental expectations on treatment of children with a cough: a report from ASPN. J Fam Pract. 1993;37:23-27

11. Mushlin AI, Appel FA. Testing an outcome-based quality assurance strategy in primary care. Med Care. 1980;18(5 suppl):1-100

12. O'Brien K, Dowell SF, Schwartz B, Marcy M, Phillips WR, Gerber MA. Cough illness/bronchitis-principles of judicious use of antimicrobial agents. Pediatrics. 1998;101(1 suppl):178-181

13. STATA [computer program]. Version 8.0. College Station, TX: STATA Corporation; 2003

14. Bureau of Health Professions. HRSA State Health Workforce Profile: California. Rockville, MD: Health Resources and Services Administration; 2000

15. Pasko T, Seidman B, Birkhead S. Physician characteristics and distribution in the US. Chicago, IL: American Medical Association Press; 2001

16. Hamm RM, Hicks RJ, Bemben DA. Antibiotics and respiratory infections: are patients more satisfied when expectations are met? J Fam Pract. 1996;43:56-62

17. Sanchez-Menegay C, Stalder H. Do physicians take into account patients expectations? J Gen Intern Med. 1994;9:404-406

18. Cooper-Patrick L, Gallo JJ, Gonzalez JJ, et al. Race, gender, and partnership in the patient-physician relationship. JAMA. 2000;282:583-589

19. Shapiro J, Saltzer E. Cross-cultural aspects of physician-patient communication patterns. Urban Health. 1981;10:10-15

20. Kaplan SH, Bandek B, Greenfield S, Rogers W, Ware JE. Patient and visit characteristics related to physicians' participatory decision-making style. Results from the Medical Outcomes Study. Med Care. 1995;33: 1176-1187

21. US Census Bureau. State and county quick facts: Los Angeles County, California. Available at: http://quickfacts.census.gov/qfd/states/06/ 06037lk.html. Accessed November 7, 2003

22. Mangione-Smith R, McGlynn EA, Elliott MN, McDonald L, Franz CE, Kravitz RL. Parent expectations for antibiotics, doctor-parent communication, and satisfaction. Arch Pediatr Adolesc Med. 2001;155:800-806

23. Stivers T. Participating in decisions about treatment: overt parent pressure for antibiotic medication in pediatric encounters. Soc Sci Med. 2002;54:1111-1130

24. Stivers T, Mangione-Smith R, Elliott MN, McDonald L, Heritage J. Why do physicians think parents expect antibiotics? What parents report versus what physicians believe. J Fam Pract. 2003;52:140-147

25. Hall JA, Irish JT, Roter DL. Gender in medical encounters: an analysis of physician and patient communication in a primary care setting. Health Psychol. 1994;13:384-392
26. Hall JA, Roter D. Medical communication and gender: a summary of research. J Gend Specif Med. 1998;1:39-42

27. Roter DL, Lipkin M Jr, Korsgaard A. Gender differences in patients' and physicians' communication during primary medical visits. Med Care. 1991;29:1083-1093

28. Burgoon JK. Nonverbal signals. In: Knapp ML, Miller GR, eds. Handbook of Interpersonal Communication. Thousand Oaks, CA: Sage; 1994:229-285

29. Curry MD, Mathews HF, Daniel HJ, Johnson JC, Mansfield CJ. Beliefs about and responses to childhood ear infections: a study of parents in Eastern North Carolina. Soc Sci Med. 2002;54:1153-1165

30. Wald ER. Acute otitis media: more trouble with the evidence. Pediatr Infect Dis J. 2003;22:103-104

31. Rosenfeld RM, Vertrees JE, Carr J, et al. Clinical efficacy of antimicrobial drugs for acute otitis media: meta-analysis of 5400 children from thirtythree randomized trials. J Pediatr. 1994;124:355-367

32. Takata GS, Chan LS, Shekelle P, Morton SC, Mason W, Marcy SM. Evidence assessment of management of acute otitis media: I. The role of antibiotics in treatment of uncomplicated acute otitis media. Pediatrics. 2001;108:239-247

33. Krishnan JA, Diette GB, Skinner EA, Clark BD, Steinwachs D, Wu AW. Race and sex differences in consistency of care with national asthma guidelines in managed care organizations. Arch Intern Med. 2001;161: 1660-1668

34. Brocklebank JC, Ray WA, Federspiel CF, Schaffner W. Drug prescribing during pregnancy. A controlled study of Tennessee Medicaid recipients. Am J Obstet Gynecol. 1978;132:235-244

35. Bronstein JM, Cliver SP, Goldenberg RL. Practice variation in the use of interventions in high-risk obstetrics. Health Serv Res. 1998;32:825-839

36. Kogan MD, Kotelchuck M, Alexander GR, Johnson WE. Racial disparities in reported prenatal care advice from health care providers. Am J Public Health. 1994;84:1521-1523

37. Davy T, Dick PT, Munk P. Self-reported prescribing of antibiotics for children with undifferentiated acute respiratory tract infections with cough. Pediatr Infect Dis J. 1998;17:457-462

38. Dosh SA, Hickner JM, Mainous AG, Ebell MH. Predictors of antibiotic prescribing for nonspecific upper respiratory infections, acute bronchitis, and acute sinusitis. J Fam Pract. 2000;49:407-414

39. Le Saux N, Pham B, Bjornson C, Pitters C. Antimicrobial use in febrile children diagnosed with respiratory tract illness in an emergency department. Pediatr Infect Dis J. 1999;18:1078-1080

40. Mangione-Smith R, Elliott MN, McDonald L, McGlynn EA. An observational study of antibiotic prescribing behavior and the Hawthorne effect. Health Serv Res. 2002;37:1603-1623 